\title{
STRATEGI KOSMONITA MALANG UNTUK MENGOPTIMALISASI KONTEN PROGRAM PEREMPUAN DALAM MEMPERTAHANKAN POSITIONING SEBAGAI RADIO BERSEGMEN PEREMPUAN
}

\author{
Hapsari Dian Sylvatri, Reza Safitri, Maulina Pia Wulandari \\ Jurusan Magister Ilmu Komunikasi, Fakultas Ilmu Sosial dan Ilmu Politik \\ Universitas Brawijaya Malang \\ hapsaridians.hds@gmail.com
}

\begin{abstract}
This study aims to optimize the content of women's programs in the form of inserts on Kosmonita radio Malang. This research is an action research study, that focuses on actions that involve researchers and community members, organizations that want to be studied.
\end{abstract}

The purpose of action research is to produce changes with certain actions to refer to social change. The object of this research is Radio Kosmonita Malang, and focuses on radio marketing strategy theory by using STP theory (segmentation, targeting, positioning) and also using SWOT analysis (Strength, Weakness, Opportunity, and Thread) as supporting theories in order to find the right strategy to optimize women's content programs in Kosmonita radio Malang. Data collection was conducted with Focus Group Discussion, interviews, making radio inserts, and conducting surveys on Kosmonita radio's listeners in Malang.

The results showed that before there was an insert, the inspiring woman program was not optimal, but after the insert, there was an optimization of women's program content.

The conclusion of this study is the addition of inspiring women's content, which contains the success stories of female in various fields, increasingly optimizing this program. Based on these conclusions, the researchers suggested to mak the insert as a talk show program that broadcast regularly on Kosmonita radio Malang and the second is regular research or survey so that it could provide new innovations for broadcast programs on Kosmonita radio Malang.

Keywords: radio, marketing strategy, swot analysis, action research.

\begin{abstract}
ABSTRAK
Penelitian ini bertujuan untuk mengoptimalisasi konten program perempuan dalam bentuk insert di radio Kosmonita malang. Penelitian ini merupakan penelitian action research, yaitu penelitian yang berfokus kepada tindakan yang melibatkan peneliti dan anggota masyarakat, organisasi yang ingin diteliti.

Tujuan penelitian action research untuk menghasilkan perubahan dengan tindakan tertentu untuk mewujukan perubahan sosial. Objek penelitian ini adalah Radio Kosmonita Malang, dan berfokus pada teori stategi pemasaran radio dengan menggunakan teori STP (segmentation, targeting, positioning) dan juga menggunakan analisis SWOT (Strength, Weakness, Opportunity, dan Thread) sebagai teori pendukung agar bisa menemukan strategi yang tepat untuk mengoptimalisasi program konten perempuan dalam radio Kosmonita Malang. Pengumpulan data dilakukan
\end{abstract}


dengan Focus Group Discussion, wawancara, membuat insert radio, dan melakukan survei terhadap pendengar radio Kosmonita Malang.

Hasil penelitian menunjukkan bahwa sebelum ada insert, program inspiring woman kurang optimal, namun setelah adanya insert tersebut terjadi optimalisasi konten program perempuan.

Kesimpulan dari penelitian ini penambahan content insert inspiring women yang berisi tentang kisah sukses tokoh perempuan dalam berbagai bidang semakin mengoptimalkan program ini. Berdasarkan kesimpulan tersebut, peneliti menyarankan untuk menjadikan insert tersebut sebagai program talkshow yang disiarkan secara regular di radio kosmonita malang dan yang kedua adalah risert atau survey secara regular sehingga dapat memberikan inovasi baru untuk program-program siar di radio kosmonita.

Kata kunci: radio, strategi pemasaran, analisis swot, action research.

\section{Pendahuluan}

Media radio dipandang sebagai kekuatan kelima (the fifth estate) setelah lembaga eksekutif (pemerintah), legislatif (parlemen), yudikatif (lembaga peradilan), dan pers/surat kabar (Ardianto, 2004, p.119). Siaran radio dibandingkan dengan media massa lainnya adalah media yang bersifat paling aktual dan imajinatif, karena khalayak hanya menggunakan indera pendengar dan pesannya pun selintas. Terlebih radio juga memiliki gaya percakapan yang mengutamakan sifat keep it simple, pendek, dan konvensional. Secara mobilitas, pendengar radio dapat mendengarkan radio sambil melakukan aktivitas sehari-hari. Selain lebih akrab, radio memiliki keunggulan lain karena bersifat auditori (untuk didengar).

$$
\text { Radio dengan beragam }
$$

keunggulannya perlahan menjelma sebagai salah satu unit usaha pada persaingan yang juga semakin ketat dalam hal memperebutkan jumlah pendengar dan pemasang iklan (Usman, 2009). Dalam situasi ini, stasiun radio ditantang untuk dapat menciptakan program siaran dengan tujuan memenuhi kebutuhan pendengarnya. Selain itu juga diperlukan kreativitas untuk membentuk ciri khas sebuah stasiun radio sebagai pembeda, supaya pendengar tetap tertarik dengan konten program yang disajikan.

Munculnya persaingan Radio dengan media massa lainnya seperti koran, majalah, dan televisi menuntut para pengelola radio untuk dapat selalu tampil menarik, informatif, dan lebih akurat. Adapun cara-cara yang ditempuh guna memenangkan persaingan tersebut adalah dengan membuat sebuah strategi pemasaran. Strategi yang digunakan dalam industri penyiaran radio sendiri menurut Albarran mencakup Segmenting, Targeting, Positioning (Morissan, 2009, p.189), dan Branding (Albarran, 2010, p.196). Keempat hal tersebut merupakan faktor penentu bertahannya stasiun radio sehingga setiap stasiun radio dituntut untuk bisa menarik pendengar dan pengiklan melalui strategi pemasarannya.

Kota Malang, Jawa Timur, merupakan sebuah wilayah di mana keberadaan radio masih diminati oleh penikmat media. Hal itu dapat dilihat melalui indikator bahwa sampai awal tahun 2018 ini, kota Malang memiliki 29 stasiun radio dengan frekuensi yang sudah penuh, yakni mulai frekuensi $89.1 \mathrm{kHz}$ (RRI Pro-1) hingga 107.9 $\mathrm{MHz}$ (Radio Sangkakala), seperti dilansir sebuah situs marketing and communications consultant Ozone.id per Januari lalu. Industri radio harus 
berusaha menarik pendengar dan pada akhirnya memaksa radio untuk memperbarui pemrogramannya, agar tetap menjadi pilihan media yang kompetitif. Salah satu upaya strategis yang dapat ditempuh oleh pengelola radio untuk bersaing adalah dengan mengoptimalkan keunikan yang dimiliki radio tersebut, yakni melalui penetapan segmentasi pendengarnya.

Saat ini telah hadir stasiun radio dengan berbagai segmen di kota Malang. Strategi pemasaran melalui segmentasi tersebut membuat masingmasing radio memiliki keunikan sendiri yang membedakan radio tersebut dari para pesaingnya. Segmentasi tiap-tiap radio tersebut juga pada akhirnya semakin memperjelas posisi radio di telinga pendengarnya, hingga sanggup bertahan dalam kompetisi industri radio di kota Malang yang kian ketat karena masing-masing juga terus berusaha berinovasi, untuk mengikuti perkembangan arus jaman demi kelanggengan eksistensi mereka. Salah satu stasiun radio yang sejak awal kemunculannya telah berbekal segmentasi yang jelas adalah Radio Kosmonita, di mana radio tersebut lebih fokus kepada dunia perempuan.

Kosmonita Malang merupakan sebuah stasiun radio bersegmentasi dengan Visi utama dari Kosmonita Malang adalah sebagai media penyedia informasi dan hiburan seputar gaya hidup kaum perempuan yang berwawasan dan bergaya, sebagaimana terangkum dalam tagline mereka, "Sahabat Perempuan dan Keluarga." Adapun tujuan Kosmonita Malang menurut profil perusahaannya adalah untuk hadir layaknya sebuah majalah udara perempuan, yang berisikan tentang features, informasi, trendsetter, wacana, pengetahuan, psikologi, serta menjadi media yang memberi wawasan tersebut dalam program talkshow atau interaktif. Hal ini dimaksudkan guna menjadikan perempuan kota Malang agar lebih open minded dan berdaya, serta lebih cerdas dalam berbagai peranannya.

$$
\text { Berdasarkan hasil analisis }
$$

Focus Group Discussion yang dilakukan oleh 60 peserta pada 24 Maret 2018 lalu, positioning radio Kosmonita dianggap masih tetap memiliki tempat di benak pendengarnya sebagai sebuah stasiun radio yang menjunjung tinggi nilai-nilai perempuan. Unsur ketepatan positioning Kosmonita didapatkan dari aspek konten program, kurasi musik, dan pemilihan waktu siar. Begitu juga dengan nama Kosmonita yang dalam persepsi pendengar sudah sesuai dengan kesan perempuan dan keluarga. Dengan modal kemampuan tersebut, Kosmonita Malang menjadi selalu siap bersaing di lingkungan industri radio kota Malang, serta tetap berpegang pada visi dan misi, peningkatan kualitas konten, dan sistem manajerial yang baik. Namun untuk dapat mempertahankan positioning tersebut, tentu dibutuhkan langkah-langkah lanjutan bagi Kosmonita guna menjaga dan memperbaiki nilai-nilai mereka dalam persepsi pendengarnya di masa depan.

Dalam merancang strategi seperti kebutuhan Kosmonita Malang tersebut, sebuah perusahaan umumnya memerlukan teknik analisa SWOT, yang menurut Rangkuti merupakan identifikasi berbagai faktor secara sistematis untuk merumuskan strategi perusahaan (Rangkuti, 2002, p.18). Penentuan strategi yang tepat dapat dimulai dengan mengenali aspek-aspek yang terbagi menjadi dua kategori, yakni aspek Strength (kekuatan) dan Weakness (kelemahan) sebagai kategori lingkungan internal perusahaan, dan Opportunity (peluang) dan Threat (ancaman) sebagai kategori lingkungan eksternal perusahaan. Keberhasilan menentukan strategi dan penerapan secara efektif dan efisien juga secara 
langsung akan memudahkan Kosmonita Malang dalam mengatasi permasalahan yang dihadapi. Karena menurut analisa FGD yang telah dilakukan juga ditemui beberapa kekurangan Kosmonita Malang dalam kaitannya sebagai radio yang mewakili perempuan, diantaranya perihal teknik penyiaran dan konten program yang bernuansa perempuan. Adanya kekurangan tersebut bila tidak segera dibenahi akan berdampak negatif terhadap eksistensi Kosmonita Malang sebagai media perempuan di masa mendatang. Maka dari itu, peneliti tertarik untuk melakukan penelitian dengan metode action research berupa tesis yang berjudul "Strategi Kosmonita Malang untuk Mengoptimalisasi Content Program Perempuan dalam Mempertahankan Positioning sebagai Radio Bersegmentasi Perempuan."

\section{Tinjauan pustaka}

Penelitian ini menggunakan teori strategi pemasaran radio yang disebut STP (segmenting, targeting, positioning) strategi segmenting terdiri dari audience yang memiliki sekumpulan kebutuhan dan keinginan yang serupa.

Segmenting adalah kelompok orang yang ingin dijangkau sebagai pendengar radio. Segmentasi dapat dilihat dari aspek demografi (usia, edukasi, dan ekonomi) dan psikografi (selera dan gaya hidup)

a. Targeting

Setelah melakukan evaluasi terhadap seluruh peluang yang ditawarkan berbagai segmen audien penyiaran, media penyiaran selanjutnya harus memilih segmen audien yang ingin dimasuki yang disebut target audien (targeting) yang akan menjadi fokus perhatian media penyiaran bersangkutan. Segmen yang dipilih bisa terdiri satu segmen atau lebih dari satu di mana media penyiaran harus menentukan tujuan dan sasaran berdasarkan target audien yang sudah dipilih serta apa yang diharapkan untuk dicapai pada audien tersebut (Morissan, 2009, p.185). Secara singkat target audien adalah memilih satu atau beberapa segmen audien yang akan menjadi fokus kegiatan-kegiatan pemasaran program dan promosi. Kadang-kadang targeting disebut juga dengan selecting karena audien harus diseleksi. Perusahaan harus memiliki keberanian untuk memfokuskan kegiatannya pada beberapa segmen audien saja dan meninggalkan segmen lainnya (Morissan, 2009, p. 185).

\section{b. Positioning}

Strategi ketiga adalah positioning dimana secara umum dalam sebuah pemasaran positioning didefinisikan sebagai tindakan merancang penawaran dan citra perusahaan agar mendapatkan tempat khusus dalam pikiran pasar sasaran. Tujuannya adalah menempatkan merek dalam pikiran konsumen untuk memaksimalkan manfaat potensial bagi perusahaan. Positioning merek yang baik membantu memandu strategi pemasaran dengan cara memperjelas esensi merek, tujuan apa yang dapat diraih pelanggan dengan bantuan merek dan bagaimana merek menjalankannya secara unik (Kotler dan Keller, 2009, p.292-293).

Positioning adalah strategi komunikasi yang berhubungan dengan bagaimana khalayak menempatkan suatu produk, merek atau perusahaan di dalam benaknya, sehingga khalayak atau audien memiliki penilaian tertentu (Morissan, 2009, p.189)

\section{b. Analisis SWOT}

Analisis SWOT adalah identifikasi berbagai factor secara sistematis untuk merumuskan strategi perusahaan. Analisis ini di dasarkan pada logika yang dapat 
memaksimalkankekuatan (strengths) dan peluang (opportunities), namun secara bersamaann dapat meminimalkan kelemahan (weekness) dan ancaman (threats) (Rangkuti,1998:18-19). Analisis SWOT juga di definiksikan sebagai suatu Teknik yang di gunakan secara luas dimana manger membuat sebuah gambaran yang cepat tentang startegi peusahaan untuk berbagai situasi (Pearce dan Robinson, 2005:166. Proses pengambilan keputusan strategis selalu berkaitan dengan pengembangan misi, tujian, srategi dan kebijakan perusahaan.

Strength (kekuatan) adalah suatu unsur dalam perusahaan yang memiliki keunggulan kompetitif dibandingkan dengan pesaing perushaan (Rangkuti, 1998:45). dapat disimpulkan bahwa strength adalah keunggulan keompetitif yang memiliki sumber daya yang tepat bagi perusahaan dibandingkan dengan pesaingnya

Weakness (kelemahan) menurut Pearce dan Robinson (2005:167) kelemahan adalah suatu keterbatasan atau kekurangan pada satu atau lebih sumber daya perusahaan yang relative terhadap kompetitir yang menanggung keefektifan kinerja perusahaan.

Opportunities (peluang) adalah kesepakatan yang memberikan dampak positif bagi perusahaan (Rangkuti, 1998:45) dalam arti kata lain opportunities (peluang) adalah situasi yang menguntungkan dan memberikan dampak positif bagi lingkungan perushaan

Threat (ancaman) menurut Pearce dan Robinson (2005:166) dijelaskan bhwa sebuah stuasi utama yang tidak menguntungkan dalam lingkungan perusahaan dan memberikan dampak negative bagi perusahaan.

Anlisis SWOT sendiri adalah membandingkan antara factor eksternal peluang (opportunities) dan ancaman (threats) dengan factor internal kekuatan (strengths) dan kelemahan (weakness) (Rangkuti, 1998:19)

\section{Metodologi penelitian}

Penelitian ini menggunakan beberapa metode penelitian yang pertama metode Focus Group Discussion. metode ini sebuah diskusi terbuka dan bersifat santai (semiterstruktur) yang diadakan oleh peneliti dan diikuti oleh sekelompok kecil orang, dengan diarahkan oleh seorang moderator, serta dirancang untuk menggali informasi mengenai topik tertentu. Teknik diskusi grup terarah secara umum dipakai dalam riset pemasaran dalam untuk mengetahui pendapat konsumen terhadap suatu produk.

Penggunaan metode ini digunakan untuk mencari positioning kosmonita malang di benak audience. yang kedua dengan wawancara mendalam terhadap operational manager dan program director kosmonita malang. Wawancara mendalam merupakan aktivitas pengumpulan data yang menuntut peneliti untuk mampu menggali informasi sebanyak mungkin dari responden penelitian. Dalam penelitian ini, wawancara dilakukan secara tertutup dan semi-terstruktur. Adapun petunjuk wawancara yang digunakan berisi daftar pertanyaan terbuka, agar mendapat jawaban secara lengkap, luas, dan terperinci. Penguasaan terhadap topik wawancara telah dilakukan oleh peneliti, karena juga berperan sebagai praktisi.

Hal ini untuk mengetahui kekuatan kelemahan peluang dan ancaman 
strength weekness opportunity and threat dari radio kosmonita malang dari sudut pandang manajemen

Yang ketiga adalah membuat program siar dan melihat perempuan opini audience dengan melakukan survei.

Dan untuk menganalisis data itu digunakan Teknik Analisa model interaktif:

a. Kondensasi Data

Adalah aktivitas reduksi data yang meliputi kegiatan seleksi, mengerucutkan,

menyederhanakan,

mengabstraksikan, hingga mentransformasi data yang telah diperoleh dari seluruh metode pengumpulan data.

b. Penyajian Data

Setelah proses kondensasi data dilakukan, maka langkah selanjutnya adalah mengorganisasikan data ke dalam masing-masing kategori. Penyajian data pada penelitian ini akan memaparkan hasil penelitian, yang menggambarkan fenomena atau keadaan sesuai dengan data yang telah direduksi.

c. Perumusan Konklusi/ Verifikasi Merupakan langkah terakhir dalam analisa interaktif, yakni dengan penarikan kesimpulan yang diambil dari hasil penelitian dan pembahasan terkait hasil temuan di lapangan.

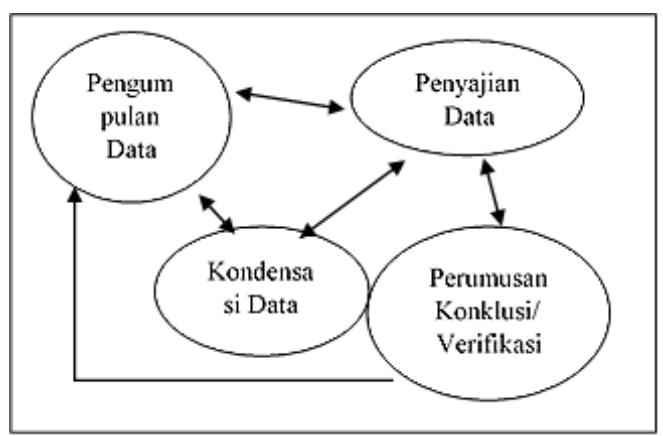

Gambar 3.2. Teknik Analisa Model Interaktif
Sumber: Miles dan Huberman (dalam Saldana, 2014, diolah 2018)

\section{Hasil penelitian}

Dalam penelitian ini ditemukan hasil analisis SWOT bahwa radio kosmonita memiliki aspek kelebihan dan kekurangan baik dari dalam radio kosmonita sendiri maupun dari luar radio kosmonita.

Dari hasil itu ditemukan beberapa opsi strategi untuk mengoptimalisasi konten program perempuan, seperti:

\section{1) Strength}

Aspek kekuatan merupakan bagian dari lingkungan internal perusahaan yang diketahui dari hasil wawancara kepada program director dan operational manager Radio Kosmonita Malang. Melalui data yang telah terkumpul diketahui bahwa terdapat tujuh faktor yang menjadi kekuatan perusahaan dalam menyusun strategi optimalisasi konten program untuk mempertahankan positioning sebagai radio bersegmentasi perempuan.

Pertama, Radio Kosmonita Malang memiliki positioning yang jelas dan telah sesuai dengan harapan perusahaan. Ketepatan positioning yang dimiliki Radio Kosmonita Malang secara garis besar selaras dengan pendapat Lesanpura (1992) mengenai langkah penentuan strategi positioning sebuah stasiun radio, yaitu Kosmonita Malang telah menjadi radio pertama dengan segmen audien perempuan yang menerima posisi stasiun radio dan menampilkan station identity atau ciri khas radio secara konsisten, baik melalui sajian format maupun musik yang dikehendaki oleh audien. Begitu juga dengan pemilihan nama dan slogan radio Kosmonita Malang yang menarik dan dapat menyatakan positioning perusahaan, hingga penyajian keunggulan pada program tertentu yang 
sesuai dengan format siaran, serta penggunaan bahasa dan gaya penyiaran yang sesuai dalam menegaskan positioning radio Kosmonita Malang. Radio Kosmonita Malang juga tidak berusaha meniru format stasiun radio lain yang ada di kota Malang. Satusatunya langkah yang belum dilakukan secara optimal oleh radio Kosmonita Malang adalah kegiatan off air yang sesuai dengan kebutuhan audien mereka.

Kedua, Radio Kosmonita Malang memiliki segmentasi audien yang jelas yakni perempuan pada rentang usia 23 - 45 tahun. Segmentasi yang jelas mempermudah tim program dalam menyusun format dan konten siaran radio, yakni ditujukan secara umum kepada keluarga dan secara khusus kepada perempuan modern yang matang, berwawasan, dan bergaya

Kekuatan positioning Radio Kosmonita Malang juga tidak terlepas dari keberadaan delapan penyiar yang memiliki karakter sesuai dengan segmentasi perusahaan, sehingga visi radio lebih mudah tersampaikan kepada audien.

Konsistensi Radio Kosmonita Malang dalam menyampaikan visi dan misi perempuan juga diakui sebagai kekuatan perusahaan oleh Ibu Didith Hadyatin, selaku operational manager perusahaan. Konsisten kepada visi dan misi pada akhirnya akan berpengaruh pada positioning di benak audien dan segmentasi yang dibutuhkan pihak pengiklan untuk memasarkan produk mereka di Radio Kosmonita Malang.

Secara umum, bekerja di dunia radio adalah sebuah aktivitas yang menyenangkan dan dapat sekaligus menjadi terapi jiwa bagi para anggota perusahaan. Hal ini ditegaskan pula oleh Ibu Didith Hadyatin, di mana lingkungan kerja yang didukung dengan musik yang dapat dinikmati oleh seluruh anggota akan membuat suasana kerja lebih baik, dan pada akhirnya akan memperbaiki kualitas sumber daya manusia di dalamnya beserta kinerja masing-masing. Hal ini juga menjadi kekuatan yang dimiliki Radio Kosmonita Malang, atau perusahaan media radio lainnya.

\section{2) Weakness}

Aspek internal lain yang diteliti dalam analisa SWOT adalah kelemahan yang dimiliki oleh Radio Kosmonita Malang. Berdasarkan data yang telah dikumpulkan terdapat sembilan faktor yang menjadi kelemahan perusahaan dalam merumuskan strategi optimalisasi konten program untuk mempertahankan positioning sebagai radio bersegmentasi perempuan. Kelemahan pertama adalah program off air yang belum terlaksana secara maksimal, seperti diutarakan program director dan operational manager Radio Kosmonita Malang.

Kelemahan pada program off air tersebut disebabkan oleh keterbatasan sumber daya manusia yang dialami Radio Kosmonita Malang. di mana selama ini tim produksi yang seharusnya menangani pelaksanaan program off air masih belum dapat dibagi secara khusus. Kurangnya sumber daya manusia juga berdampak pada kekosongan tim marketing Radio Kosmonita Malang, yang secara langsung mengurangi daya pemasaran perusahaan, baik dalam memasarkan konten program atau ruang iklan sebagai salah satu sumber pemasukan perusahaan secara finansial. Selain itu, keberadaan teknologi digital berupa social media juga belum dipergunakan secara optimal oleh tim promosi Radio Kosmonita Malang.

Program director Radio Kosmonita Malang mengakui bahwa promosi program melalui media sosial belum linier dengan siaran on air. Kelemahan lain dalam upaya optimalisasi konten program adalah kurangnya jumlah penyiar perempuan 
Radio Kosmonita Malang, yang saat ini masih berjumlah total delapan orang, dengan masing-masing 4 penyiar perempuan dan laki-laki. Hal ini secara tidak langsung dikhawatirkan dapat mempengaruhi positioning Radio Kosmonita Malang sebagai media bersegmentasi perempuan, walaupun dalam hasil focus group discussion yang telah dilakukan audien tidak mempermasalahkan jenis penyiar selama karakternya sesuai dengan konten program yang dibawakan.

Di luar konten program, Radio Kosmonita juga masih memiliki sejumlah kekurangan lain dalam lingkup internal perusahaan. Segmentasi yang ditentukan selama ini di sisi lain juga berpengaruh terhadap adanya batasan pada kategori pengiklan. Segmentasi yang secara konsisten dilakukan membuat Radio Kosmonita Malang dituntut untuk selektif terhadap jenis iklan yang akan diterima dan disiarkan. Dari sisi manajemen perusahaan, operational manager Radio Kosmonita Malang mengakui bahwa sistem yang selama ini diterapkan oleh manajemen masih belum sepenuhnya bersifat profesional, atau lebih ke arah manajemen kekeluargaan. Hal ini pada akhirnya berpengaruh pada proses manajemen sumber daya manusia.

Adapun kekurangan lain secara internal adalah rendahnya sinyal Radio Kosmonita Malang, yang berakibat pada kualitas suara yang diterima audien siaran.

\section{3) Opportunity}

Aspek peluang merupakan unsur dari lingkungan eksternal perusahaan yang diteliti dalam analisa SWOT. Berdasarkan data yang diperoleh dari focus group discussion dan wawancara telah diketahui adanya sembilan peluang yang dimiliki Radio Kosmonita Malang, untuk merumuskan strategi guna mempertahankan positioning sebagai radio dengan segmentasi perempuan. Peluang utama yang dapat dimanfaatkan secara optimal adalah Radio Kosmonita Malang sudah memiliki tempat di benak audien sebagai radio yang konsisten dengan visi "Sahabat Perempuan dan Keluarga”.

Selain itu, segmentasi audien perempuan yang dipilih oleh Radio Kosmonita Malang berbeda dengan stasiun radio lokal lainnya, yang sekaligus menjadikan Kosmonita sebagai radio perempuan satu-satunya di kota Malang. Penentuan segmentasi tersebut pada satu sisi dapat membatasi jenis iklan yang akan masuk, namun di sisi lain justru menjadi kekuatan tersendiri jika diterapkan secara konsisten. Hal ini pada akhirnya menjadi peluang tersendiri bagi Radio Kosmonita Malang, terlebih ketika radio lain justru mengambil langkah perubahan segmentasi, di mana hal ini justru menguatkan posisi Radio Kosmonita Malang di benak audien. Dengan posisi tersebut, Radio Kosmonita Malang memiliki ruang yang dibutuhkan bagi produk tertentu untuk mempromosikan barang bersegmentasi sesuai.

\section{4) Threat}

Aspek ancaman adalah unsur lingkungan eksternal perusahaan yang juga dipertimbangkan dalam analisis SWOT. Berdasarkan data yang telah terkumpul dari focus group discussion dan wawancara, ditemukan adanya lima ancaman yang harus dapat diatasi oleh Radio Kosmonita Malang dalam upaya merumuskan strategi optimalisasi positioning stasiun radio dengan segmentasi perempuan di kota Malang. Ancaman pertama yang harus dihadapi oleh Radio Kosmonita Malang adalah keberadaan stasiun radio lokal yang mulai merambah segmentasi perempuan di kota Malang. Meskipun secara umum radio pesaing berawal dari konsep media keluarga, namun hal ini patut diwaspadai oleh Kosmonita yang 
sejauh ini telah menjadi radio perempuan pertama di kota Malang.

Ancaman kedua adalah permasalahan yang secara umum dihadapi pula oleh para pelaku bisnis dari segala bidang, yakni era transisi konsumen dengan kemunculan generasi audien baru (Gen Z) bagi Radio Kosmonita Malang. Keberadaan generasi $\mathrm{Z}$ atau juga disebut generasi centennial memiliki karakteristik berbeda dari generasi-generasi sebelumnya dalam analisis demografis model Cohort. Generasi centennial lahir terhitung sejak tahun 1997 ketika teknologi internet mulai mendominasi kehidupan masyarakat di dunia. Generasi centennial juga dikenal sebagai digital native, karena telah terpapar teknologi digital berbasis online sejak kelahirannya. Kemunculan generasi centennial merupakan ancaman sekaligus peluang yang harus mampu dihadapi oleh produsen di seluruh bidang, tidak terkecuali Radio Kosmonita Malang yang bergerak di bidang media.

Keberadaan generasi audien baru menuntut Radio Kosmonita Malang untuk memasuki persaingan dengan media baru seperti televisi dan internet, baik secara format konten program maupun kemasan penyajiannya. Media-media baru telah menjadi sarana utama bagi audien radio saat ini dengan dukungan gadget yang memiliki keunggulan dalam hal mobilitas dan bersifat lebih praktis daripada radio.

\section{a. Matriks SWOT Radio Kosmonita Malang}

Matriks SWOT adalah alat untuk menyusun faktor-faktor strategis perusahaan, yang pada penelitian ini akan digunakan untuk merumuskan strategi optimalisasi program perempuan, dalam upaya mempertahankan positioning Radio Kosmonita Malang sebagai stasiun radio bersegmentasi perempuan di kota Malang. Matriks ini dapat menggambarkan secara jelas bagaimana peluang dan ancaman yang dihadapi perusahaan Radio Kosmonita Malang akan mampu disesuaikan dengan kekuatan dan kelemahan perusahaan demi mencapai tujuan yang diharapkan. Berikut ini adalah tabel matriks SWOT dari hasil analisa lingkungan internal dan lingkungan eksternal yang dimiliki perusahaan Radio Kosmonita Malang:

Tabel 4.4

Matriks SWOT Radio Kosmonita Malang

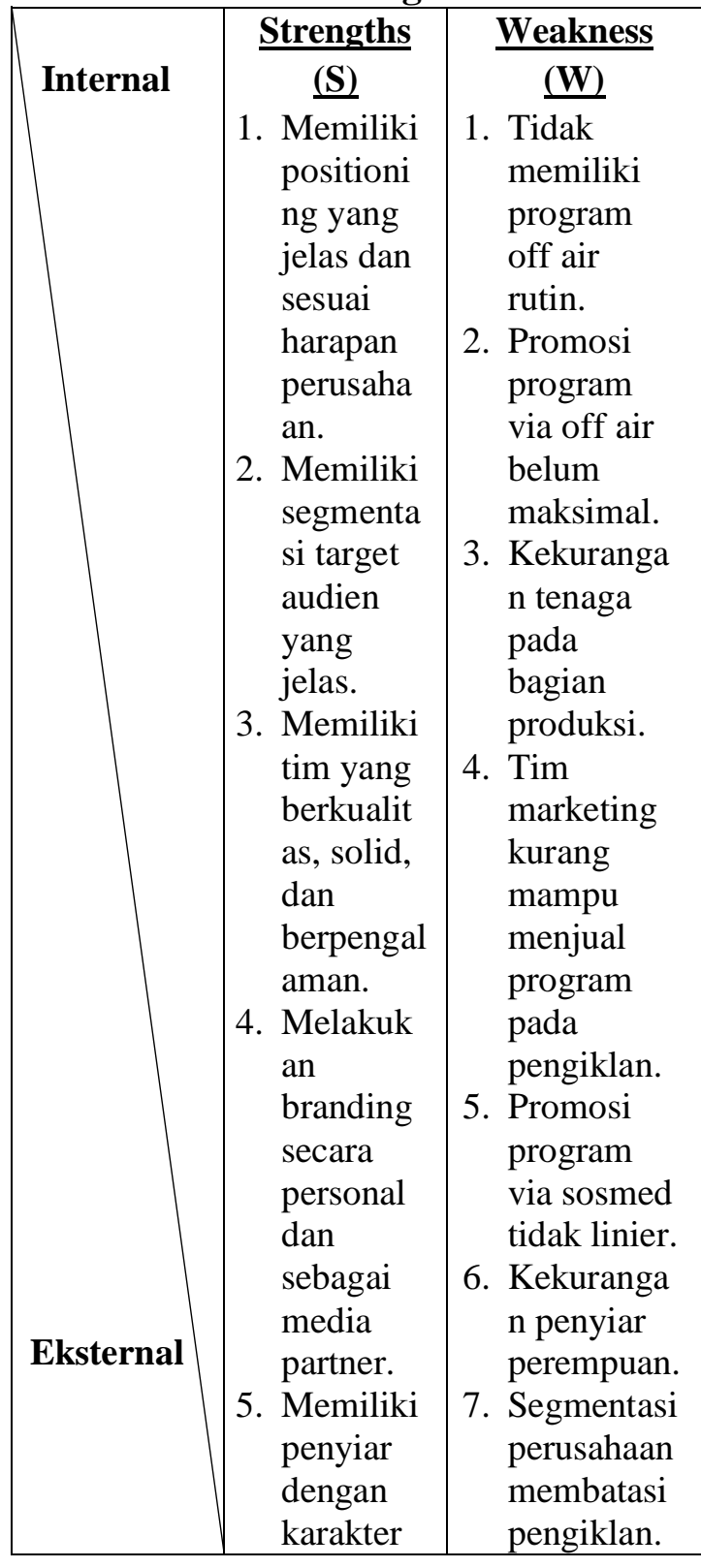




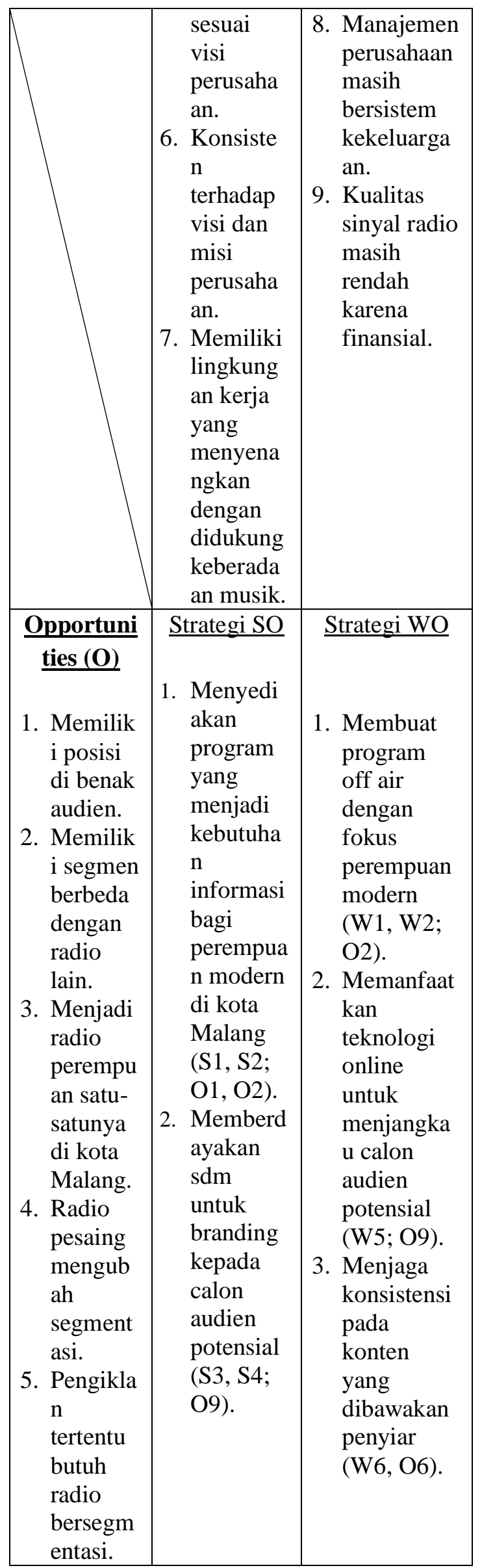

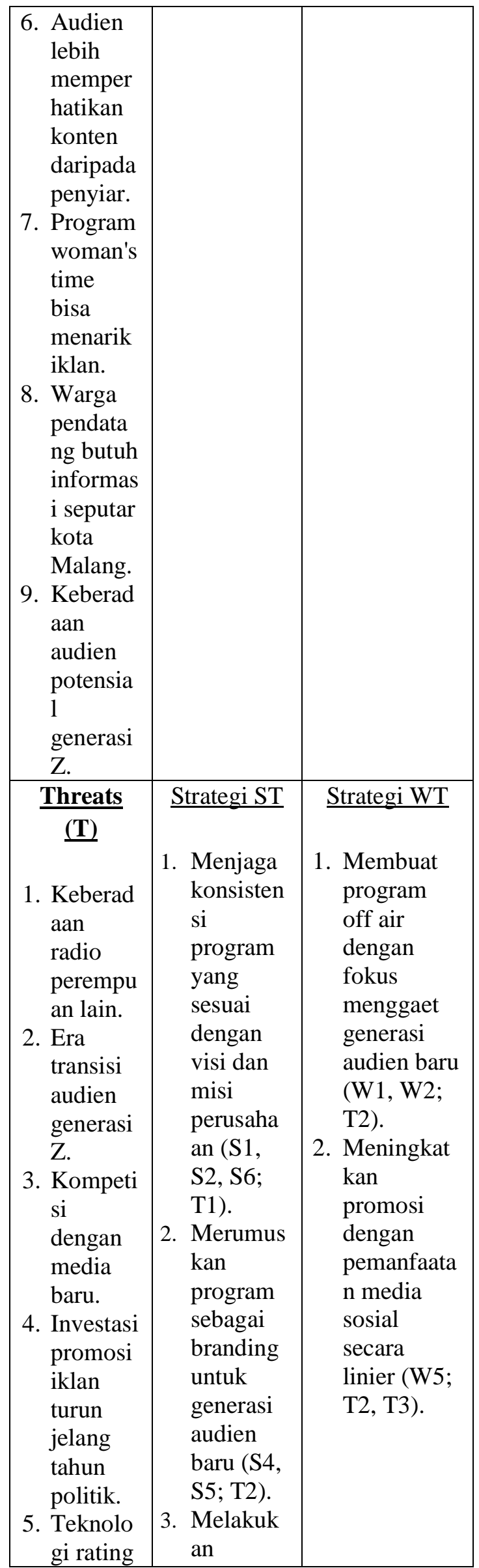


JURNAL NOMOSLECA

Volume 5 Nomor 1, April 2019

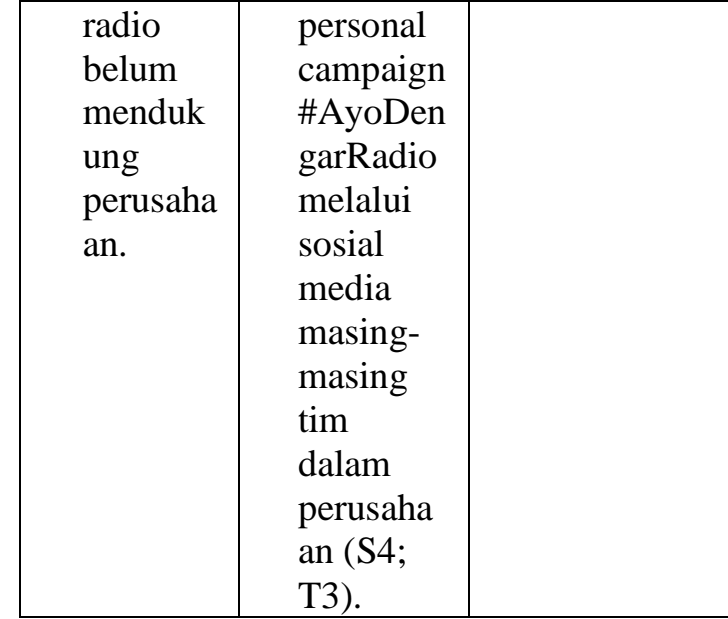

Sumber: Focus group discussion dan wawancara dengan program director dan operational manager Radio Kosmonita Malang (Maret - Agustus 2018)

Dari hasil analisis swot dapat disimpulankan peneliti merumuskan sbahwa stategi yang cocok dalam upaya penajaman konten program perempuan itu berupa program insert bertema kisah sukes perempuan inspiratif dikota malang yang berjudul inspiring women .

\section{Adapun format clock program insert di tayangkan top of hour}

(gambar)

\begin{tabular}{|c|c|c|c|}
\hline $\begin{array}{l}\text { Struk } \\
\text { tur }\end{array}$ & Waktu & Durasi & $\begin{array}{l}\text { Running } \\
\text { Order }\end{array}$ \\
\hline $\begin{array}{l}\text { Openi } \\
\text { ng }\end{array}$ & $\begin{array}{l}14.00- \\
14.05\end{array}$ & 5 ' & $\begin{array}{ll}- & \text { Time } \\
& \text { signal } \\
\text { - } & \text { Promo } \\
\text { Bulanan } \\
\text { - } & \text { Jingle } \\
& \text { turn over } \\
\text { - } & \text { Promo } \\
\text { program } \\
\text { - } & \text { Penyiar } \\
\text { membuk } \\
\text { a } \\
\text { program } \\
\text { dengan } \\
\text { menyebu } \\
\text { tkan call } \\
\text { sign } \\
\text { radio } \\
\text { station }\end{array}$ \\
\hline
\end{tabular}

\begin{tabular}{|c|c|c|c|}
\hline & & & $\begin{array}{l}\text { menyebu } \\
\text { tkan } \\
\text { nama, } \\
\text { dalam } \\
\text { program } \\
\text { apa, } \\
\text { opening } \\
\text { sesuai } \\
\text { tema } \\
\text { bulan }\end{array}$ \\
\hline $\begin{array}{l}\text { Song } \\
2: 1\end{array}$ & $\begin{array}{l}14.05- \\
14.15\end{array}$ & $10^{\prime}$ & \\
\hline Talk 1 & $\begin{array}{l}14.15 \\
14.18\end{array}$ & $3^{\prime}$ & Info \\
\hline Song 1 & $\begin{array}{l}14.18- \\
14.22\end{array}$ & $4^{\prime}$ & \\
\hline $\begin{array}{l}\text { Comm } \\
\text { ercial } \\
\text { (spot) }\end{array}$ & $\begin{array}{l}14.22- \\
14.26\end{array}$ & $4^{\prime}$ & $\begin{array}{l}\text { Jingle radio } \\
\text { Memutar } \\
\text { iklan } \\
\text { Jingle }\end{array}$ \\
\hline Song 2 & $\begin{array}{l}14.26- \\
14.30\end{array}$ & $4^{\prime}$ & \\
\hline Talk 2 & $\begin{array}{l}14.30- \\
14.33\end{array}$ & $3^{\prime}$ & Adlibs \\
\hline Song 1 & $\begin{array}{l}14.33- \\
14.37\end{array}$ & $4^{\prime}$ & \\
\hline Insert & $\begin{array}{l}14.37- \\
14.39\end{array}$ & 2 ' & $\begin{array}{l}\text { Smash } \\
\text { Insert } \\
\text { inspiring } \\
\text { women } \\
\text { Smash }\end{array}$ \\
\hline Song 1 & $\begin{array}{l}14.39- \\
14.43\end{array}$ & $4 '$ & \\
\hline Talk 3 & $\begin{array}{l}14.43- \\
14.45\end{array}$ & $2^{\prime}$ & Info \\
\hline Song 1 & $\begin{array}{l}14.45- \\
14.50\end{array}$ & 5 , & \\
\hline $\begin{array}{l}\text { Comm } \\
\text { ercial } \\
\text { (spot) } \\
2\end{array}$ & $\begin{array}{l}14.50- \\
14.55\end{array}$ & 5 , & $\begin{array}{l}\text { Jingle } \\
\text { Memutar Iklan } \\
\text { (4) } \\
\text { jingle }\end{array}$ \\
\hline Song 1 & $\begin{array}{l}14.55- \\
15.00\end{array}$ & 5 , & \\
\hline
\end{tabular}

Setelah dilakukan action research berupa penayangan insert 
inspiring women selama 3 bulan makan dilaksanakan survey tentang respon atau refleksi terhadap audiens apakah insert tersebut sampai pesannya terhadap audiens.

Dampak dari program insert terhadap audiens

Adanya penambahan insert program baru "Inspiring Women" ternyata mendapat perhatian dari responden Berdasarkan diagram yang ada dapat diketahui bahwa insert program "Inspiring Women" menjadi pilihan sebagian besar responden, yakni $39,9 \%$ atau sebanyak 32 pendengar dari 80 responden. Jawaban hasil survei pendengar juga menunjukkan bahwa mayoritas responden menganggap insert program adalah konsep menarik dan sesuai dengan konten perempuan radio Kosmonita Malang.

Insert program "Inspiring Women" adalah realisasi tindakan yang digagas peneliti bersama tim program untuk menyusun strategi optimalisasi konten program perempuan radio Kosmonita Malang, dalam upaya mempertahankan positioning sebagai radio bersegmentasi perempuan. Karenanya dibutuhkan pula tanggapan pendengar mengenai kemampuan pesan yang terdapat pada insert program tersebut dalam menjangkau audien radio. masa depan sebuah radio akan sangat bergantung pada konten, di mana kemampuan media untuk terkoneksi dengan pendengar lokal dan komunitas sekitar akan menjadi penentu keberadaan dan keberhasilan media tersebut. Sementara salah satu aspek yang dapat menentukan keberhasilan radio adalah keterkaitan media dengan program acara yang disiarkan. Keterkaitan di sini dapat dimaknai sebagai segmentasi dan positioning Kosmonita Malang sebagai radio perempuan, sehingga keterkaitan konten program perempuan yang dapat diterima dan dipahami audien menjadi syarat utama eksistensi mereka.
Berdasarkan survei pendengar yang telah dilakukan, dapat disimpulkan bahwa sebagian besar responden mampu menerima dan mengolah pesan yang disampaikan melalui insert program "Inspiring Women",

Adapun beberapa saran juga diperoleh dari audien melalui survei pendengar yang telah dilakukan terkait insert program di radio Kosmonita Malang. Saran terhadap format insert program yang disiarkan diantaranya adalah: Pertama, perlunya penanda dalam setiap insert program. Hal ini diperlukan agar pendengar dapat membedakan masing-masing insert program, yang selama ini diputar secara random pada program siaran tertentu sebagaimana terlihat pada tabel 4.5 tentang jadwal siar insert program "Inspiring Women" di atas. Pemberian judul yang turut diperdengarkan pada masingmasing insert program menjadi masukan yang positif bagi pengembangan konten selanjutnya. Kedua, terkait pemilihan backsound atau musik latar yang menjadi pengiring narasi pada insert program radio Kosmonita Malang. Pendengar menilai bahwa kurasi musik pengiring dalam insert program berperan penting untuk membentuk suasana komunikasi, dengan tujuan agar pesan yang disampaikan lebih terasa, sehingga menjadi lebih mudah dirasakan dan dipahami konteksnya.

Ketiga, pendengar merasa perlu adanya konten insert program yang lebih interaktif dengan audien, misalnya dalam bentuk sapaan. Audien merasa bahwa keberadaan kalimat sapaan sebagai bentuk interaksi akan membuat hubungan penyiar dan pendengar lebih dekat, dan secara emosional dapat meningkatkan suasana hati pendengar. Keempat, adanya saran 
untuk menghadirkan tokoh-tokoh inspiratif dalam "Inspiring Women" ke dalam program talkshow yang dimiliki radio Kosmonita Malang. Tujuannya adalah supaya kisah yang ditampilkan dalam insert program dapat diceritakan secara lebih detail, tanpa harus dibatasi dengan durasi yang hanya sebanyak 30 detik. Adapun kritik dari pendengar mengenai format insert program, terutama "Inspiring Women" adalah di mana cara penyampaian dari narasumber dinilai tidak sebaik cara komunikasi yang dilakukan penyiar radio Kosmonita Malang. Hal ini dapat dipahami karena masing-masing penyiar memiliki kemampuan lebih dalam berkomunikasi secara verbal, yang tentunya tidak dimiliki oleh orang lain secara umum. Kritik tersebut dapat menjadi masukan bagi tim program radio Kosmonita Malang dalam hal pembuatan naskah dan proses rekaman audio yang dilakukan kepada masingmasing narasumber selanjutnya.

Selain saran terhadap format program, diperoleh pula saran mengenai tema-tema yang perlu diangkat dalam insert program radio Kosmonita Malang. Diantaranya merupakan tema populer yang masih menjadi permasalahan secara umum bagi masyarakat, terutama perempuan di Indonesia, misalnya masalah keluarga seperti poligami, kekerasan dalam rumah tangga, dan isu-isu ekonomi masyarakat yang berhubungan dengan usaha kecil menengah. Permasalahan tersebut dianggap audien radio Kosmonita Malang sebagai problem umum yang banyak diangkat, tetapi belum dapat disikapi secara efektif karena minimnya ruang berbagi untuk pihak yang dirugikan. Kemudian tema seputar pengembangan diri perempuan Indonesia, manajemen stres, dan kisah perempuan Indonesia dalam menghadapi problematika kodrati mereka. Hal ini layak mendapat apresiasi dari radio Kosmonita, mengingat peran media yang sangat penting dalam menyuarakan keinginan konsumen mereka

\section{Kesimpulan}

Strategi optimalisasi konten program perempuan radio Kosmonita Malang dilakukan dengan dasar strategi pemasaran, yakni menentukan segmentasi, target audien, dan mengevaluasi positioning di benak pendengar. Segmentasi Kosmonita Malang adalah perempuan modern yang matang, berwawasan, dan bergaya. Sedangkan audien yang menjadi target pendengar radio Kosmonita Malang adalah perempuan pada rentang usia 23 - 45 tahun dan berada di wilayah jangkau frekuensi radio Malang Raya, meliputi Kabupaten Malang dan Kota Batu. Positioning Kosmonita Malang sebagai radio perempuan tidak berubah, sebagaimana diketahui melalui focus group discussion yang diadakan pada awal penelitian dan diikuti oleh pendengar setia Kosmonita Malang. Data berupa strategi pemasaran perusahaan tersebut kemudian diolah dengan metode analisis SWOT untuk mengevaluasi kekuatan dan kelemahan radio Kosmonita Malang. Selanjutnya peneliti bersama tim program dan atas persetujuan manajer operasional merumuskan sebuah insert program berjudul "Inspiring Women" sebagai upaya penajaman konten perempuan di radio Kosmonita Malang, yang mulai disiarkan pada 19 November 2018 dan masih diputar hingga saat ini.

"Inspiring Women" adalah
sebuah pernik program yang
mengangkat tema tentang kisah singkat
dari perempuan inspiratif di Kota
Malang. "Inspiring Women" diputar
sebagai sisipan program acara on air


selama weekdays pada program "Kosmonita Pagi", dan "Woman's Talk". Materi awal "Inspiring Women" diperoleh melalui tujuh narasumber dari berbagai bidang. Satu minggu setelah insert program diputar secara on air, peneliti yang juga bertindak sebagai praktisi radio mulai melakukan survei pendengar untuk mengetahui respon audien atas program "Inspiring Women". Hal ini penting dilakukan dalam action research karena hasil evaluasi berupa refleksi dari tindakan dapat mempengaruhi keberlanjutan penelitian, seperti telah dijelaskan dalam dialectic action research spiral. Adapun survei pendengar dilakukan selama satu bulan hingga akhir bulan Desember 2018, melalui kuesioner yang diikuti oleh 80 responden secara daring.

Berdasarkan hasil survei diketahui bahwa mayoritas pendengar paling menyukai program musik di radio Kosmonita Malang (52,5\%), dengan program weekdays "Kosmonita Pagi" sebagai acara yang paling banyak disukai oleh responden (56,3\%). Insert program secara keseluruhan mendapat perhatian dari sekitar $70 \%$ responden, dan lebih dari $80 \%$ responden menganggap insert program adalah konten yang menarik, serta 92,5\% responden menilai insert program radio Kosmonita sudah sesuai dengan konten perempuan. Program "Inspiring Women" mendapat apresiasi terbanyak dari responden selaku pendengar radio Kosmonita Malang $(39,9 \%)$ di antara insert program lainnya, walaupun tanpa melalui promosi program sebagaimana publikasi konten program baru sebelumnya. Diketahui pula bahwa $68,8 \%$ responden menyatakan sudah mampu menerima pesan yang disampaikan dalam insert program "Inspiring Women" dan dapat dimaknai dengan adanya hubungan antara radio dengan dengan pendengar, sebagai salah satu aspek penentu keberadaan dan keberhasilan suatu media massa. Aspek lain yang dapat menentukan keberhasilan radio adalah keterkaitan media secara konseptual dengan program siaran, di mana dapat dimaknai bahwa keterkaitan konten program perempuan yang dapat diterima dan dipahami adalah syarat utama eksistensi radio Kosmonita Malang, sebagai radio dengan segmentasi perempuan dan memiliki positioning yang kuat sebagai radio perempuan di Kota Malang.

\section{Daftar Pustaka}

Akbar \& Usman. (2009). Metode Penelitian Sosial. Jakarta: Bumi Aksara.

Albarran, Alan B. 2010 Media Economics (Understanding Market, Industries, Concept). Iowa State Universty Press.

Ardianto, E.L. 2004. Komunikasi Massa: Suatu Pengantar. Bandung: Simbiosa Rekatama Media

Kotler, phillip, dan Kevin Lane Keller. 2009. Manajemen Pemasaran jilid 2. Jakarta: Penerbit Erlangga

Morissan, Allexander. 2009. Manajemen Media Penyiaran; Strategi Mengelola Radio \& Televisi. Jakarta: Kencana Prenada Media Group

Pearce II, John A dan Robinson

Richard B.Jr. (2008).

Manajemen Strategis 10. Salemba Empat, Jakarta.

Rangkuti, F. 1998. Analisis SWOT Teknik Membedah Kasus Bisnis. PT. Gramedia Pustaka Utama, Jakarta. 